\title{
Att mottaga främmande
}

\author{
Cajsa Wabllund och andra duktiga värdshusvärdinnor $i$ det tidiga \\ 1800-talets Finland
}

RESANDET BLEV PÅ I7OO-TALET på ett annat sätt möjligt och mer lockande för européer än det varit under tidigare sekler. Trots krigföring på skilda håll i Europa blev resandet i allmänhet tryggare, säkrare och bekvämare tack vare bland annat bättre vägar och vagnar. Resande drog även fördel av att det växte fram ett tätare nätverk av gästgiverier och värdshus. Med de nya bad- och kurhotellen uppstod dessutom en ny standard för trivsel och komfort vid inkvartering. ${ }^{1}$ Nöjesresenärer började också ses som en möjlighet till att göra goda affärer. I många städer investerade därför penningstarka män i fashionabla badanstalter och promenadparker med musikunderhållning och servering. ${ }^{2}$

I. Hans Heiss, "Selbständigkeit bis auf Widerruf? Zur Rolle von Gastwirtinnen bis I9I4", Irene Bandhauer-Schöffmann \& Regine Bendl (Hrsg.), Unternebmerinnen. Geschichte und Gegenwart selbständiger Erwerbstätigkeit von Frauen, Frankfurt am Main: Peter Lang 200o, s. 49-87; Per Hartmann, Hotellens kulturhistoria i Västerlandet, Stockholm: Mimer 1983; Ernst M. Wallner, Von der Herberge zum Grandhotel. Wirtshäuser und Gastlichkeit. Geschichte, Wirtshausnamen, Wirtshausschildler, Konstanz: Rosgaerten 1968.

2. Hannah Greig, The Beau Monde. Fashionable Society in Georgian London, Oxford: Oxford University Press 2013, s. 63-80; Peter Clark, European Cities and Towns, 400-200o, Oxford: Oxford University Press 2009, s. 155-157, I9I-199, 310-315; Tammy M. Proctor, "Home and Away: Women, Popular Culture and Leisure", Deborah Simonton (ed.), The Routledge History of Women in Europe since I700, London \& New York: Routledge 2007, s. 299-340, https://doi.org/Io.4324/9780203969120; Auvo Kostiainen et al., Matkailijan ihmeellinen maailma: matkailun historia vanhalta ajalta omaan aikaamme, Suomalaisen Kirjallisuuden Seuran toimituksia 977, Helsinki: SKS 2004; Antoni Mączak, Travel in Early Modern Europe, Cambridge: Polity Press 2003 [1995]; Hermann Bausinger, Klaus Beyrer, Gottfried Korff (Hrsg.), Reisekultur. Von der Pilgerfahrt zum modernen Tourismus, München: C.H. Beck I99I. 
Frankrike och Italien, de främsta resmålen för adelssönernas traditionella grand tour, sågs med nya ögon efter att Laurence Sterne presenterat en ny, romantisk inställning till resandet i $\sin A$ Sentimental Journey through France and Italy (r768). Boken blev en succé och modell för en del senare reseskildringar. ${ }^{3}$ Etablerade sydliga resmål utmanades norröver av ett spännande nytt resmål, nämligen S:t Petersburg. Under Katarina II:s och Alexander I:s regeringstider byggdes staden upp till en storslagen metropol som sedan lockade talrika västeuropeiska resenärer. ${ }^{4}$ De som attraherades av exotiska men ändå någorlunda riskfria resmål valde Skandinavien och då i synnerhet Lappland, med vilket man avsåg Torneå och Tornedalen. ${ }^{5}$ Okunniga om och ovana vid förhållandena i norr som många utländska resenärer ändå var, kunde resan i verkligheten bli mera riskabel och påfrestande än de tänkt sig.

Finlands roll var i början att tjäna som genomfartsland mellan Stockholm och S:t Petersburg eller på färden till och från Lappland. Först på 180o-talet, då ryska resenärer upptäckte Finland, blev landet ett resmål i sig. Forsen Imatra en dagsresa från Viborg/Vyborg och parken Monrepos nära Viborg blev de första populära resmålen. Senare var Brunnshuset i Helsingfors under ett tiotal år på modet bland petersburgska och balttyska resenärer. ${ }^{6}$

3. Den upplaga som jag haft tillgång till var avsedd för tyska läsare: Mr. Yorick [Laurence Sterne], A Sentimental Journey through France and Italy. Mit erklärenden Anmerkungen und einem Wortregister für junge Leute, Halle: Regerschen Buchhandlung I794 [I768]. Det blev sedermera populärt att använda "Sentimental Journey" i boktitlar.

4. En tidig resehandbok om S:t Petersburg var t.ex. Heinrich Storch, Gemäblde von St. Petersburg, I-II, Riga: Hartknoch I793, svensk övers. Beskrifning om St. Petersburg, I-2 Delen, Stockholm: Johan Pehr Lindh I799-I80o, engelsk övers. The Picture of Petersburg, London: T. N. Longman \& O. Rees I8or.

5. H. Arnold Barton, Northern Arcadia. Foreign Travellers in Scandinavia, I765-1815, Carbondale \& Edwardsville: Southern Illinois University Press 1998; Tony Lurcock, 'Not So Barren or Uncultivated'. British Travellers in Finland I760-I830, London: CB Editions 2oro, s. I-2I.

6. Nathanaëlle Minard-Törmänen, An Imperial Idyll. Finland in Russian Travelogues (1810-I860), Bidrag till kännedom av Finlands natur och folk 199, Helsingfors: Societas Scientiarum Fennica 2016; Lurcock, 'Not So Barren or Uncultivated', S. I4O-I4I, 202; Sven Hirn, Imatra som natursevärdhet till och med I87o. En reselitterär undersökning med lokalhistorisk begränsning, Bidrag till kännedom av Finlands natur och folk 102, Helsingfors: Finska Vetenskaps-Societeten r958; Päiviö Tommila, Helsinki kylpyläkaupunkina I830-I850-luvuilla, Entisaikain Helsinki VI, Helsinki: Helsinki-seura I955. 
Utländska resenärer erbjöds ofta att logera hos lokala ståndspersoner. Därför är det mer sällsynt än man kunde tro med beskrivningar av möten mellan resenärer och dem som tog emot resande på gästgiverier och i värdshus eller senare på hotell. I glesbygden sökte resande nattlogi på en bondgård eller i någon stuga vid vägkanten. ${ }^{7}$ Välbärgade resande från andra länder hade i regel med sig minst en tjänare, men tjänarna sågs inte som resesällskap utan som en nödvändighet och nämns därför endast i förbigående, om de alls nämns, i reseberättelserna. Resenärer vana vid betjäning och helt annorlunda förhållanden hade ofta ganska liten förståelse för de svårigheter som folk på landsbygden i norr hade då de försökte tillmötesgå kraven på mat och sovplats för resenärerna och deras tjänare.

I resebeskrivningar från I7oo-talets Sverige med Finland och I80o-talets Finland omnämns flera traktörer, somliga vid namn eftersom de var borgare. Värdinnan på en prästgård eller i ett annat högreståndshem omnämns alltid och oftast vid namn. Däremot nämns andra kvinnor som såg till att utländska resenärer och deras tjänare erhöll mat och sovplats bara sporadiskt, såsom värdinnor på gästgiverier och i värdshus eller hustrur på bondgårdar. Dessa kvinnor betraktades på samma sätt som pigor, tvätterskor, tjänare och betjänter: deras tjänster sågs som en självklarhet i det dåtida samhället.

Den enda värdshusvärdinna vars namn alls antyds i de samtida reseskildringar om Finland som jag läst är Cajsa Wahllund i Helsingfors som får beröm av Captain George Matthew Jones. ${ }^{8}$ Hade vi bara reselitteratur att gå till skulle vi alltså inte få höra eller läsa annat än anekdoter om anonyma kvinnor. Men tack vare tidningars

7. Sven Hirn,"Suomi matkailumaana vuoteen i887", Sven Hirn \& Erkki Markkanen, Tuhansien järvien maa: Suomen matkailun historia, Helsinki: Matkailun edistämiskeskus \& Suomen matkailuliitto I987, s. 7-I45; Yrjö Soini, Vieraanvaraisuus ammattina. Kulttuuribistoriallinen katsaus Suomen majoitus-ja ravitsemiselinkeinojen kehitykseen I-II, Helsinki: Otava I963; Arvid Julius, Sverige med främlingsögon. Utdrag ur utländska resenärers skildringar före I80o, Stockholm: Wahlström \& Widstrand I930.

8. George Matthew Jones, Travels in Norway, Sweden, Finland, Russia, and Turkey, Vol. I., London: John Murray I827, s. 27I f. Jones tackade "Mademoiselle Chat", och år I822, då resan ägde rum, fanns det ingen annan i Helsingfors än Cajsa Wahllund som han kan ha åsyftat. Cajsa Wahllund undertecknade ibland sina tidningsannonser"Cath. Wahllund" (aldrig "Cajsa"). Titlar och yrkesbeteckningar anges i den här essän i regel så som de står i källmaterialet. 
och därmed tidningsannonsers tillkomst kan vi följa hur kvinnor på I8oo-talet trädde fram som professionella värdshusvärdinnor. Eftersom några tidningar publicerade namnen på "anmälda resande" och deras värdar och värdinnor, ${ }^{9}$ är det möjligt att diskutera kvinnors betydelse som värdshusvärdinnor.

I denna essä vill jag, med hjälp av uppgifter om sådana värdshusvärdinnor som vi känner till namnet, lyfta fram betydelsen av de talrika anonyma män och kvinnor som vid värdshus, gästgiverier och skjutsstationer under hästarnas tidevarv gjorde resandet landvägen möjligt. Jag börjar med att presentera utländska resenärers iakttagelser av lokala kvinnor som på ett eller annat sätt var dem till nytta. Värdinnor på prästgårdar och i andra högreståndshem samt deras tjänarinnor har jag dock inte beaktat. Efter det presenterar jag tre värdshusvärdinnor som vi vet mera om: Cajsa Wahllund (I77I-1843), Hedvig Astenius (1783-I860) och Sara Motti (död I844). De nämns så ofta som värdinnor för"anmälda resande" i tidningarna att jag kan använda informationen som underlag för en diskussion om möten mellan utlänningar och finländare i värdshus. Avslutningsvis granskar jag värdshus som socialt neutrala mötesplatser. I sina restauranger förde Wahllund, Astenius och Motti samman inhemska och utländska resande, fina och mindre fina, bekanta och okända.

\section{RESENÄRERS IAKTTAGELSER AV KVINNOR SOM BETJÄNADE DEM}

De utlänningar som skrev om sina resor i Sverige och Finland mottogs i regel som ståndspersoner. I sina reseberättelser försummade de inte att beskriva mötena med ståndspersoner på orten. Hur vanligt folk såg på utländska resenärer beskrivs mera sparsamt i reseberättelserna. ${ }^{10}$ I resenärers beskrivningar framställs den lokala befolkningen ofta

9. "Förteckning öfver i Staden vistande resande" (rubriken varierade) som Päiviö Tommila använt lämpar sig inte för mina syften. Tommila, Helsinki kylpyläkaupunkina, Liite I, s. 207-252; Helsingfors Tidningar (HT) 7/7, 2I/7, 7/8 I84I, 9/7, I3/7 I842, 24/7, 3I/7 I844, I6/7 I845, 25/7 I846, I7/7, 4/8 I847, 28/6, 29/7 I848, 25/7 I849.

Io. Ett undantag i detta avseende var Mrs. Alec [Ethel B.] Tweedie, Through Finland in Carts, London: Nelson 1897, s. 87, 223, 231, 252, 263 f., 273, 312. Se även Mary Wollstonecraft, Letters Written during a Short Residence in Sweden, Norway, and Denmark, London: J.Johnson I796, s. I2, 4 O f., https://doi.org/IO.4324/978I315578538. 
som en tyst skara som intresserat betraktar de främmande. ${ }^{11}$ Trots att mötena mellan främmande och ortsbor i det hierarkiskt uppbyggda ståndssamhället alltid var ståndsbundna, ter sig dylika möten mellan två skilda världar på ett kuriöst sätt jämlika, eftersom båda parterna betraktade varandra med en antropologisk blick. Däremot var konstellationen självklart ojämlik när det gällde kvinnor som på ett eller annat sätt betjänade utländska resenärer.

Utländska resenärer iakttog förstås lokala kvinnor. ${ }^{12}$ På r6oo-talet förvånade sig greve Lorenzo Magalotti och markis Alessandro Bichi, samt på I70o-talet professor Diedrich Herman Hegewisch, över kvinnor som rodde resande i Stockholm och dess skärgård. ${ }^{13}$ År I804 beundrade John Carr Stockholms tvätterskor. ${ }^{14}$ I slutet av I8oo-talet förvånade sig Mrs. Tweedie över kvinnors tunga kroppsarbete i Helsingfors och i Jakobstad. ${ }^{15}$

På den svenska och finska landsbygden iakttog utländska resenärer lokala kvinnors utseende, klädsel, beteende, arbete och sysselsättning. ${ }^{16}$ På den svenska landsbygden blev utländska män angenämt

II. M. [Réginaud] Outhier, Journal d'un voyage au nord, En I736. Eं I737., Paris: Pidget \& Durand I744, s. 38, 57; Reginaud Outhier, Journal frän en resa $i$ Norden år I736-I737. Den franska gradmätningsexpeditionen i Tornedalen I736-I737, övers. Gunvor \& Arne Nordberg, Luleå: Tornedalica I982, s. 3I, 40; Matthew Consett, A Tour through Sweden, Swedish-Lapland, Finland and Denmark, Stockton: R. Christopher I789, s. 58; Ch. St-Julien [Saint-Julien], Impressions et souvenirs de Finlande, Saint-Pétersbourg: Pluchart I834, s. I48. Saint-Julien var lécteur i fransk litteratur vid Kejserliga universitetet i S:t Petersburg.

I2. Christine Bladh, "Med främlingars ögon", Christine Bladh (red.), Rodderskor på Stockholms vatten, Stockholm: Stockholmia 2008, s. I45-152.

13. Lorenzo Magalotti, Sverige under år 1674 , övers. Carl Magnus Stenbock, Stockholm: P.A. Norstedt \& Söner I9I2, s. II; Julius, Sverige med främlingsögon, s. 63, 69, II5.

I4. John Carr, A Northern Summer or Travels round the Baltic through Denmark, Sweden, Russia, Prussia, and Part of Germany, in the Year 1804, London: Richard Phillips I805, s. I79 f.

15. Tweedie, Through Finland in Carts, s. Io, 327. Ibland förväxlades orterna Jakobstadt (Jēkabpils) i Baltikum och österbottniska Jakobstad.

16. Madame de Staël, Mémoirs de Madame de Staël (Dix années d'exil). Ouvrage posthume publie en I8I8 par M. le duc de Broglie et M. Le baron de Staël. Nouvelle édition, Paris: Bibliothèque-Charpentier 1818, s. 454 f.; Wollstonecraft, Letters Written during a Short Residence, s. 27, 37; Clarke, Travels in Various Countries of Scandinavia, s. 512, 520; Carr, A Northern Summer, s. I84; William Rae Wilson, Travels in Russia E'c. Eंc. Vol. II, London: Longman, Rees, Orme, Brown, and Green I828, s. I48, I52-158, I76; L. Morel-Fatio, Paysages du Nord, Paris: A. Courcier I856 [faksimil, le Centre culturel français de Helsinki 200I], s. I2r; Consett, A Tour through Sweden, s. 62 f., 
överraskade då unga kvinnor satt gränsle över hästen när de red den till skjutsstationen, skötte trötta hästar och fungerade som kuskar för resenärerna. ${ }^{17}$ På den finska landsbygden nära Imatra blev den romantiskt sinnade fransmannen Ch. Saint-Julien på i83o-talet helt förtrollad av den vackra rodderskan Marie Weström, dotter till färjkarlen vid Siitola värdshus vid floden Vuoksi ("Voxa"). Saint-Julien diktade upp en tragisk historia om henne, men hans beskrivning av Maries forsränning med fadern förefaller trovärdig. ${ }^{18}$

Utländska resenärer hade varierande erfarenheter av gästgiverier och värdshus i I700- och I80o-talens Sverige och Finland. ${ }^{19}$ På skjutsstationer och gästgiverier på landsbygden och i stugor vid vägen plågades de resande ofta av ohyra och smutsiga sovplatser. En del resenärer föredrog att sova i sin resvagn. ${ }^{20}$ Sängar var en raritet på landsbygden. ${ }^{21}$ Därför blev resenärerna glatt överraskade om huset,

Jones, Travels in Norway, Sweden, Finland, s. 205; Lurcock, 'Not So Barren or Uncultivated', s. III, I27, I66; Tony Lurcock, No Particular Hurry. British Travellers in Finland 1830-19I7, London: CB Editions 2013, s. 27, 77-78, 86.

I7. Jones, Travels in Norway, Sweden, Finland, s. 68; Charles Boileau Elliot, Letters from the North of Europe; or a Journal of Travels in Holland, Denmark, Norway, Sweden, Finland, Russia, Prussia, and Saxony, London: Henry Colburn \& Richard Bentley I832, s. 203.

I8. St-Julien, Impression et souvenirs, s. 57-68, I08; Hirn, Imatra som natursevärdhet, s. $170-182,206-208$.

19. Edward Daniel Clarke, Travels in Various Countries of Europe, Asia and Africa. Part the Third, Scandinavia, Section the Second, London: T. Cadell I823, s. 300, 3II, 318, 326, 33I, 366, 375, 385, 443, 459, 465, https://doi.org/ro.5962/bhl.title.I219ı1; William Coxe, Travels into Poland, Russia, Sweden, and Denmark. In Five Volumes, Vol III, London: T. Cadell I792, s. 270 f., 274; Jones, Travels in Norway, Sweden, Finland, s. 66-68, I27-I29, I98, 223, 250 f., 26I, 28I; Boileau Elliot, Letters from the North of Europe, s. 219 f., 243, 257, 260 f.; Carr, A Northern Summer, s. I9I, I93, 202, 210; Wollstonecraft, Letters Written during a Short Residence, s. I7 f., 44-46.

20. N. Wraxall, Jun., A Tour through some of The Northern Parts of Europe, particularly Copenhagen, Stockholm, and Petersburgh. In a series of letters. The Second Edition, corrected, London: T. Cadell I775, s. 75, 82-93, IOI f., I78-I79, I85-I88; Clarke, Travels in Various Countries of Europe, s. 300, 3II, 318, 326, 331, 366, 375, 385, 443, 459, 465; Clarke, Travels in Various Countries of Scandinavia, s. 508, 5II; Coxe, Travels into Poland, Russia, Sweden, and Denmark. III, s. 270 f., 274; Jones, Travels in Norway, Sweden, Finland, s. 66-68, I27-I29, I98, 223, 250 f., 26I, 28I; Boileau Elliot, Letters from the North of Europe, s. 219 f., 243, 257, 260 f.; Carr, A Northern Summer, s. I9I, 193, 202, 210; Wollstonecraft, Letters Written during a Short Residence, s. I7 f., 44-46; Lurcock, 'Not So Barren or Uncultivated', s. I8, 35, 4I, 45 f., Io9, II4, I23, I6o, I62, I82, I92 $\mathrm{f}$.

2I. Eftersom William Coxe som reste i Sverige år I779 påstod att t.o.m. ”de fattigaste 
sovplatsen och värdinnan var rena och propra. Matthew Consett, som mest hade stött på dåliga gästgiverier, fann år $\mathrm{I} 786$ till sin förvåning $\mathrm{i}$ den lilla byn Sunnanå i Norrland ett utmärkt gästgiveri-värdshus vars värdinna på alla sätt gjorde sitt bästa. ${ }^{22}$ Sommaren 1896 i Norra Savolax i östra Finland blev Mrs. Tweedie och hennes syster lika tacksamma, då de på väg till Kajana oväntat kom till ett bra gästgiveri-värdshus: "Here at last, thank heaven, we found a majatalo [värdshus] which was properly inspected. There were iron bedsteads and clean mattresses." I detta värdshus, som beskrivs som "charming", smakade allt som ställdes på bordet gott. Framme i Kajana vågade sig dessa två modiga engelska damer faktiskt på forsränning. ${ }^{23}$

I april ı80o anlände italienaren Giuseppe Acerbi med sin reskamrat till Uleåborg. De var på väg till Torneå, men på grund av menföret var de tvungna att stanna i staden längre än planerat. Fördröjningen blev emellertid mycket angenäm: "Vi kommer alltid att ha ett angenämt minne av vår vistelse $\mathrm{i}$ Uleåborg." Vid sidan av den lokala societeten hade värdshusvärdinnan en stor betydelse för gästernas trivsel:

Vår värdinna arbetade från morgon till kväll för att kunna duka fram en furstlig måltid för oss och för att göra vår tillvaro angenäm i alla hänseenden. Hon lät slakta kalvar, grisar och oxar, uttryckligen för oss. Havens och älvarnas mest värdefulla byten skaffades fram för vår skull och köptes utan tanke på kostnaderna.

Värdshusvärdinnan strävade till och med efter att variera deras menyer från dag till dag med olika soppor. Acerbi skrev att räkningen för det rikhaltiga och lyxiga kosthållet och allt annat han, hans reskamrat och deras tjänare hade konsumerat under veckorna $\mathrm{i}$ Uleåborg var helt skälig. ${ }^{24}$ Deras vistelse måste ha tärt hårt på värdshusets ekonomi.

kojorna i Sverige voro aldrig utan denna bekväma sak [säng]”, resonerade Arvid Julius att"Coxes uppgifter torde väl närmast gälla gästgivargårdarna". Julius, Sverige med främlingsögon, s. IIo. Se även Clarke, Travels in Various Countries of Europe, s. 383.

22. Consett, A Tour through Sweden, s. I4, I6, 19, 47, 49.

23. "Här hittade vi äntligen, tack gode Gud, ett värdshus som var ordentligt granskat. Där fanns järnsängar och rena madrasser.” Tweedie, Through Finland in Carts, s. 274 f.; om forsränning s. 288-310.

24. "Our residence at Uleåborg will ever be pleasing to our recollection", "Our hostess was labouring from morning to night to supply us with a plentiful table, and to 
Edward Daniel Clarke logerade samtidigt som Acerbi i samma värdshus i Uleåborg i ett"litet, men rent och bekvämt rum”. Enligt honom hade Acerbi och hans italienska reskamrat nio tjänare med sig. ${ }^{25}$

På väg från Helsingfors till Åbo i slutet av i820-talet övernattade William Rae Wilson med sitt resesällskap på ett bra värdshus i "Ominia-Bijorby" nära Salo. Tydligen var dessa utländska gäster mera generösa än de inhemska vid betalningen av räkningen, eftersom värdinnan inte visste hur hon skulle visa sin tacksamhet. ${ }^{26}$ Några år senare skulle fransmannen Saint-Julien med sin reskamrat övernatta i Viborg. Den enda rysktalande stadsbo som Saint-Julien lyckades finna rekommenderade "tyska änkans" värdshus för fransmannen. Saint-Julien och hans reskamrat hade inget att klaga på i änkefruns värdshus. ${ }^{27}$ "Tyska änkan" i Viborg måste ha varit änkan efter den tyskfödde traktören Ertman. ${ }^{28}$

På väg från Sulkava till S:t Michel stannade Saint-Julien med sin reskamrat på gästgiveriet i Jockas (Juva) där den vackra, blonda, unga värdinnan bjöd dem på en utmärkt omelett och god hembrygd, "petite-bière". Detta var lyx jämfört med vad resenärerna i allmänhet fătt att äta och dricka. Saint-Julien glömde inte att nämna andra tjusiga kvinnor som vid något tillfälle serverade dem, men inte heller glömde han värdinnan som kokade kaffe till dem på ett gästgiveri, trots att hon annars inte framställs som särskilt hjälpsam. ${ }^{29}$

make our situation comfortable in every other respect. She killed calves, pigs and oxen, expressly on our account. The most precious spoils of the sea and rivers were procured for us, and purchased without regard to economy." Värdshusets ägare var enligt Acerbi en handlande med efternamnet Feldman. Antagligen var värdinnan hans fru. Joseph [Giuseppe] Acerbi, Travels through Sweden, Finland, and Lapland to the North Cape in the Years 1798 and 1799 , Vol. I, London: Joseph Mawman I802, s. $254,276,277$ (citat).

25. "... small, but clean and comfortable apartment". Clarke, Travels in Various Countries of Scandinavia, s. 496 (citat), 502.

26. Wilson, Travels in Russia, s. I77; Julius, Sverige med främlingsögon, s. I3I.

27. St-Julien, Impressions et souvenirs, s. 25-26.

28. Hon skötte ensam värdshuset åtminstone år 1827 , möjligen redan tidigare, och titulerades år I832 "Traktörskan Ertman". Wiburgs Wochenblatt 24/12 I824, 9/6 I827; $H T_{21} / 7$ I832 ("Resande."). Om dottern Amalia Ertman (Ertmann), se Finlands Allmänna Tidning (FAT) 3/8 I844 ("Notificationer"). Ertman skrevs ibland Ertmann eller Erdtman.

29. St-Julien, Impression et souvenirs, s. I28, I93, 220, 224 f., 296. Med "petite-bière" avsåg fransmännen eventuellt svagdricka. 
Under Europas så kallade galna år 1848 valde Emmanuel Galitzin, en rysk furste, det fridfulla och ordentliga Storfurstendömet Finland som sitt resmål. Han och hans reskamrat samt deras betjänt reste från S:t Petersburg till Torneå. De övernattade i gästgivargårdar och Galitzin utformade skildringen av resan som en resehandbok som tog läsaren från gästgiveri till gästgiveri. I Rantasalmi blev de mottagna av två damer som hade goda intentioner men inte helt lyckades med dessa; gästgiveriet var dock rent och trivsamt. Efter att de lämnat Kuopio anlände de till byn "Savokaniarvo", där gästgiveriet var berömvärt, trots att det till det yttre var anspråkslöst. Både värdinnan och linnet var oklanderligt rena,"la crème" (grädden) var utmärkt och dukningen med silverbestick till och med något lyxig. På väg tillbaka från Torneå anlände de till ett gästgiveri-värdshus i Brahestad som överträffade alla andra. Värdinnan visade dem till ett rum där sängarna, i sig en raritet, var mjuka och mattorna tjocka. Dessutom tycks värdinnan ha haft ett gemensamt språk med dem, vilket inte hade varit fallet i Uleåborg. ${ }^{30}$

I ödemark och skärgård sökte resenärer härbärge i bondgårdar eller i nödfall i vilken stuga eller koja som helst. Deltagarna i den berömda franska gradmätningsexpeditionen i Tornedalen I736-I737, under ledning av Pierre Louis Moreau de Maupertuis, underkastade sig verkliga strapatser i ödemarken. Fransmännen och de lokala män de anställt som roddare och byggare av mätningstorn och mycket annat övernattade i de mest varierande förhållanden, även vid en lägereld. Fransmännen återvände därför gärna till bondgårdar de redan besökt, såsom till "det goda huset" nära Aavasaksa och forsen Kattilankoski där de blivit väl mottagna och serverade god kvällsvard. ${ }^{31}$

Resan över Ålands hav kunde på sommaren vara behaglig, men på vintern var den alltid riskfylld. ${ }^{32}$ På sommaren I804 var färden en ren

30. Emmanuel Galitzin, La Finlande: notes recueilles en 1848 pendant une excursion de Saint-Pétersbourg à Torneo, Paris: Bertrand I852, Tome I, s. 206-209, 267 f., 355-357; Tome 2, s. I8-2I, 52 f., IO4, I33-I37.

3I. Outhier, Journal d'un voyage au nord, s. 54-94, 97-Ir6, "nous avons dîné à Hyougsing, dans la Maison où nous avions été si bien reçus le 30 Juillet", s. Ir6; Outhier, Journal från en resa $i$ Norden, s. 38-63, 66-79, "Vi åt middag i Juoksenki i det hus, där vi den 30 juli blivit så väl mottagna.", s. 79.

32. Julius, Sverige med främlingsögon, s. I20; Coxe, Travels into Poland, Russia, Sweden, $I V$, s. I6-26; Lurcock, 'Not So Barren or Uncultivated', s. Io9 f., I47-I48, I74 f. 
idyll för John Carr, och en fiskargård tedde sig som ett litet paradis där den unga fiskarhustrun lagade och dukade fram kvällsmat åt Carr och hans reskamrat. ${ }^{33}$ Däremot hade den vintriga färden från Grisslehamn några år tidigare varit livsfarlig för Edward Daniel Clarke. I beskrivningen av strapatserna skymtar enstaka kvinnor. Värdinnan på gästgiveriet i Sottunga var stolt över husets renhet: inga löss eller skinnbaggar i sängarna. På fastlandet fanns det inget härbärge mellan Varstala och Åbo, men i byn Vinkkilä lyckades Clarke och hans resesällskap övertala en änkefru att ta emot dem i sitt hus över natten, mot löfte att de skulle betala som i en gästgivargård. ${ }^{34}$ Vintern I852 blev färden från Grisslehamn lika farlig för Louis Léouzon Le Duc. I sin reseberättelse beskriver han värdinnan på gästgiveriet i Eckerö som hjälpsam och döttrarna som tjänstvilliga. På Seglinge var det svårt för fiskarhustrun att ställa fram en måltid för resenärerna och deras tjänare, då det bara fanns lite strömming, kål och potatis i huset. Följande dag, då Léouzon Le Duc och hans resesällskap var på väg till Kumlinge, kokade värdinnan på gästgiveriet kaffe till dem. ${ }^{35}$

Reseberättelser från ståndssamhällets tid påminner avlägset om de reseberättelser som europeiska resenärer under kolonialtiden skrev om länder som var koloniserade av något europeiskt land. Utländska resenärer i Sverige och Finland kunde, liksom vita européer i kolonialländer, vänta sig att bli erbjudna logi hos lokala ståndspersoner. En dåtida resenär, Charles Boileau Elliot vid Bengal Civil Service, insåg likheten då han beskrev Sverige: "här, precis som i Indien, är varje gentlemans hem öppet för den resande" ${ }^{36}$ Fransmännens inledningsvis något nedlåtande inställning till de lokala män de anställt i Tornedalen förändrades dock och blev mera uppskattande under de gemensamma strapatserna i ödemarken. Tydligare var likheten i beskrivningar av de vintriga färderna över Ålands hav då de två utländska resenärerna

33. Carr, A Northern Summer, s. I82-I88; om fiskargården s. I84.

34. Clarke, Travels in Various Countries of Europe, s. 302-382; om Sottunga s. 352 f.; om Vinkkilä s. 382, 384; svenskt särtryck En resa på Aland vintern 1799 , övers. Jocelyn Palmer, bearb. Gunilla Lundberg-Kelly, Mariehamn: Ålands litteraturföreningÅlands skötbåtsförening I982, s. 49 f., 69-71.

35. Léouzon Le Duc, Les Îles d'Aland, Paris: L. Hachette 1854, s. I7-56; om kvinnorna s. $25,28,49-5$ I.

36. "... here, as in India, every gentleman's house is open to the traveler." Boileau Elliot, Letters from the North of Europe, s. 208, även s. 218. 
faktiskt riskerade de lokala männens liv. För utländska resenärer utgjorde de män och kvinnor som stod dem till tjänst en del av en infrastruktur som de tog för given.

\section{FÖRETAGSAMMA VÄRDSHUSVÄRDINNOR}

Vid sekelskiftet I8oo tillät magistraterna i större svenska och finska städer efterfrågan styra då det gällde tillstånd att öppna värdshus och krogar. I början av I80o-talet fanns det i Stockholm i runda tal 700 krögerskor, ${ }^{37}$ samtidigt som utländska resenärer klagade över bristen på ordentliga värdshus för resande. ${ }^{38} \mathrm{I}$ Helsingfors fördes en ganska liknande politik, vilket var i enlighet med borgarnas intressen. ${ }^{39}$ I slutet av I70o-talet fanns det i Åbo vid sidan av "krögarnas stora skara" bara ett bättre värdshus, Seipells värdshus, där bland andra Edward Daniel Clarke tillbringade sin första natt i Åbo. ${ }^{40}$ I Borgå och Viborg var det i stort sett likadant: talrika krogar men bara ett eller två värdshus. ${ }^{41}$ Även bättre värdshus serverade förstås alkohol, men de strävade efter att skilja sig från mängden av krogar och tavernor som var avsedda för lägre samhällsgrupper.

I åtminstone Åbo, Helsingfors, Borgå och Viborg fanns det under första hälften av I80o-talet bättre värdshus där kvinnor ansvarade för hela verksamheten. Deras värdshus var avsedda för respektabla gäster och förutom inkvartering erbjöd de gästerna en bra restaurang. För ortsborna profilerade sig värdshusen som klubbrum. Att driva värds-

37. Christine Bladh,"Kvinnors dubbla beroende av sprit. Beskänkta kvinnor och kvinnor med utskänkning i Stockholm I8I2-1816", Christine Bladh, Elisabet Cedersund \& Jan-Erik Hagberg (red.), Kvinnor och män som aktörer och klienter, Stockholm: Nerenius \& Santérus 1997, s. II-40.

38. Acerbi, Travels through Sweden, Finland, and Lapland, s. 32; Carr, A Northern Summer, s. II8; Jones, Travels in Norway, Sweden, Finland, s. II6, I36.

39. Jessica Parland-von Essen, Affärer, allianser, anseende. Konsten att tillböra eliten $i$ Helsingfors ca I740-I820, Helsingfors: Schildts 20IO, s. 77-89; Ester-Margaret von Frenckell, Offentliga nöjen och privata i Helsingfors $1812-1827$, med en historisk översikt, Helsingfors: Söderström \& Co. I943, s. r6o f., 237, $244 \mathrm{f}$.

40. Oscar Nikula, Åbo stads historia I809-1856, Åbo: Åbo stad 1973, s. I32; Clarke, Travels in Various Countries of Europe, s. 385, 443. I Clarke står namnet felaktigt i formen "Scippell".

4I. Torsten Hartman, Borgå stads historia, andra delen, Helsingfors: G.L. Söderström I907, 4I3 f.; W. Ruuth, Viborgs stads historia. Första bandet, Helsingfors: [Viborgs stad] I903, s. 633-635. 
husverksamhet var en bra marknadsnisch för kvinnor; värdshusen räknades inte till de borgerliga näringarna och driften krävde inget stort kapital. ${ }^{42}$

I Åbo fick källarmästare Seipell år I8oo en konkurrent då värdshusvärdinnan Eva Falck ${ }^{43}$ hyrde det nya Brinkala eller Bremerska huset vid Stortorget och öppnade ett högklassigt värdshus. När kung Gustav IV Adolf sommaren I8o2 besökte Åbo i sällskap av drottningen, blev de höga gästerna trakterade av Eva Falck. Hennes värdinneskap i Brinkalahuset blev dock kortvarigt. ${ }^{44}$ Nästa professionella värdshusvärdinna i staden var Christina Catharina (Cajsa) Wahllund, som flyttat till Åbo från Stockholm. Hon började anspråkslöst år ı8ı2, men var redan 1813 ansvarig för värdshusverksamheten i det nya Societetshuset i Åbo och I8r6 för Seipells värdshus. ${ }^{45}$ Det finns emellertid inga uppgifter om resande i Eva Falcks eller Cajsa Wahllunds värdshus i Åbo.

Hösten I8I9 flyttade Cajsa Wahllund till Helsingfors. ${ }^{46}$ Det är oklart exakt var hennes första värdshus var beläget. En tidningsnotis från februari 1820 antyder att hon då hade sitt värdshus i kommerserådet Heidenstrauchs hus. ${ }^{47}$ Även i Helsingfors flyttade hon ofta sin värdshusverksamhet, men höll sig ändå alltid i kvarteren vid eller kring Stora torget (Senatstorget). Läget signalerade att det var fråga om ett

42. Marjatta Rahikainen,"Urban Opportunities. Women in the Restaurant Business in Swedish and Finnish Cities, c. I800-1850", Johanna Ilmakunnas, Marjatta Rahikainen \& Kirsi Vainio-Korhonen (eds), Early Professional Women in Northern Europe, c. I650-1850, London \& New York: Routledge 2017 (2018), s. I77-I95, https://doi. org/10.4324/978I315578538.

43. För en kortfattad biografi, se Kirsi Vainio-Korhonen, "Falck, Eva”, Biografiskt lexikon för Finland I. Svenska tiden, Helsingfors: SLS \& Stockholm: Atlantis 2008, s. 209-210.

44. Kirsi Vainio-Korhonen,"Mamselli Falckin tarina eli kaupunkihistorian tutkimaton sukupuoli", Ihmiset ovat kaupunki, Turun Historiallinen Arkisto 53, Turku: Turun Historiallinen Yhdistys I999, s. 65-78; Kirsi Vainio-Korhonen, "Ravintoloitsija Eva Falck (I764-I8ro) ja kuningasparin juhlaillallinen”, Anu Lahtinen, Sini Ojala \& Kirsi Vainio-Korhonen (toim.), Naisten kaupunki. Turkulaisten naisten historiaa, Turun Historiallinen Arkisto 6I, Turku: Turun Historiallinen Yhdistys 2010, s. 108-Io9; Oscar Nikula, Åbo stads historia I72I-I809, Andra Bandet, Åbo: Åbo stad I972, s. 650-654; Soini, Vieraanvaraisuus ammattina I, s. 2II-215.

45. Nikula, Abo stads historia I809-1856, s. 50I-5II.

46. Man vet inte exakt när hon flyttade, men i början av augusti I8I9 var hon ännu i Åbo. Åbo Allmänna Tidning 5/8 I8I9.

47. Sveriges ambassad finns för närvarande i detta hus. 
bättre värdshus och att räkningen var därefter. I december I820 hade hon sitt värdshus vid Stora torget i Sunnska (Sundska) huset där hon också själv bodde. I oktober I823 flyttade hon med sin värdshusrörelse till Mattenska huset vid torget. På hösten I83i anmälde hon att "den värdshusrörelse som jag hittills idkat uti $\mathrm{Hr}$ Landshöfdingen $\mathrm{Hjärnes}$ hus fortsättes nu uti Hr Walleens gård vid Fredsgatan”, ${ }^{48}$ alltså nuvarande Alexandersgatan. ${ }^{49}$ På sommaren 1834 meddelade hon att hon flyttat sitt värdshus till"Handlanden Backmans gård"vid Fabiansgatan och på hösten samma år att hon flyttat det till"Handlanden Löffströms gård [...] vid Fredsgatan nära Universitetshuset”. Hösten I835 flyttade hon sitt värdshus till "Handlanden Baranoffs hus" vid Stora torget. ${ }^{50}$ Utöver reseskildringen av Captain George Matthew Jones som år I822 logerade hos Cajsa Wahllund, ${ }^{51}$ finns det inga samtida uppgifter om utländska resenärer förrän lokaltidningarna år 1829 började publicera "anmälda resande”. På I870-talet publicerades en dagbok av Elizabeth Mary Grosvenor, markisinnan av Westminster. I dagboken skrev hon att hon och hennes make i Helsingfors 1827 fann "tolerable rooms", hyfsade rum, i "Mademoiselle Washlund's hotel". ${ }^{52}$

Möjligtvis logerade även William Rae Wilson hos Cajsa Wahllund. Han reste sommaren 1825 genom de baltiska provinserna till S:t Petersburg och sedan vidare längs kustvägen från Viborg till Åbo. Han beskrev värdshuset i Helsingfors och dess värdinna så här:

Värdshuset som var hyfsat fint förestods av en dam med patagonisk resning och kinderna insmorda i rouge. Det föreföll som om denna dam inte ännu var trött på livet i celibat, även om hon redan var omkring sextio. Hennes hår hade inte med tiden tunnats ut eller blivit gråsprängt, för det var mycket tjockt och svart. [...] Priset för inkvarteringen var sex rubel, för middag med utmärkt vin en och en halv. ${ }^{53}$

48. von Frenckell, Offentliga nöjen och privata, s. 206; FAT 9/2, 4/12 1820, 5/4, I5/5, 9/10 I823, 28/9, 3/IO I83I; HT 28/9, 5/I0 I831.

49. Fredsgatan blev Alexandersgatan 1835 , se Carolus Lindberg \& Gabriel Rein, "Stadsplanering och byggnadsverksamhet", Helsingfors stads historia, III delen, forsta bandet, Helsingfors: Helsingfors stad I950, s. 52-53.

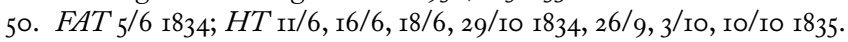

5I. Se not 8.

52. Se vidare Lurcock, 'Not so Barren or Uncultivated', s. 204.

53. Wilson, Travels in Russia, s. I73 f. 
Visserligen passar åldern in på Cajsa Wahllund, och på ett porträtt som bevarats har hon fint mörkt hår och kanske lite rouge på kinderna, men annars motsvarar inte Wilsons bild senare minnesbilder av henne. Däremot stämmer "middag med utmärkt vin" överens med andra minnesbilder av Cajsa Wahllunds verksamhet, eftersom hennes två restauranger, Kajsaniemi och Emilienburg ("Sparbanken"), blev legendariska bland helsingforsborna. ${ }^{54}$

Kuststaden Borgå fick en ny roll då Finland blev en del av ryska kejsardömet. På färden mellan Helsingfors och S:t Petersburg låg Borgå lagom till för en vilopaus för resande och hästar. Trots detta fanns det i staden ännu på 1830-talet bara ett värdshus värt namnet, "Fru Astenii värdshus". Jakov Grot, professor i ryska språket, brukade logera hos Hedvig Astenius på sina resor till och från S:t Petersburg. ${ }^{55}$ Det är okänt när Hedvig Astenius, född Sjöström, började med sitt värdshus, kanske år 1820 . Bland borgåborna blev Hedvig Astenius värdshus på 1830-talet känt som stadens främsta restaurang och klubbrum. ${ }^{56}$ William Rae Wilson beskrev värdshuset i Borgå och dess värdinna så här:

På värdshuset i Borgå togs vi emot av en enorm värdinna [... som] verkade fast besluten att allting skulle visas upp i så fördelaktig dager som möjligt, för hon beställde fram sex stora ljus som skulle placeras på bordet. En riklig kvällsmåltid bestående av vilt dukades fram tillsammans med en enorm spritflaska i kristall. ${ }^{57}$

54. Rahikainen, "Urban Opportunities", s. 185-I88.

55. Utdrag ur J. Grots brevväxling med P. Pletnjov I, övers. Walter Groundstroem, Skrifter utgifna av Svenska litteratursällskapet i Finland (SSLS) Io6, Helsingfors: Svenska litteratursällskapet i Finland (SLS) I9I2, s. 273, 294; Utdrag ur J. Grots brevväxling med P. Pletnjov II, SSLS irg, Helsingfors: SLS i915, s. 43-44, 83-84, I6o.

56. Gunnar Mårtenson, Fru Astenii värdshus. Bilder från runebergstidens Borgå, Helsingfors: Holger Schildts Förlag I942, s. 22-23; HT II/I I837; FAT Io/5, 28/10 I837; Rahikainen,"Urban Opportunities”, s. I88-ı9o; Anneli Mäkelä-Alitalo, Borgå stads bistoria III:I I809-1878, Borgå: Borgå stad 2000, s. I76-I80.

57. "At the inn in Borgo we were received by a gigantic landlady [... who] seemed resolved that everything should be shown off to the best advantage, for she ordered six large candles to be set upon the table. A bountiful supper of game was set out, with an enormous crystal bottle of spirits." Wilson, Travels in Russia, s. I6r. 
På det porträtt som finns bevarat av Hedvig Astenius ser hon ut som en anständig kvinna av lägre borgerskap. ${ }^{58}$ Man kan anta att Wilsons kommentarer gäller henne, då det år 1825 inte fanns något annat värdshus i Borgå som motsvarar beskrivningen.

Det bästa värdshuset i Viborg i början av I8oo-talet ägdes av en italienare, signor Giovanni (Johan) Motti, som räknades till stadens handlande borgare. Trots att han tog bra betalt, prisades värden och värdshuset av flera utländska resenärer. Till resenärernas belåtenhet bidrog att döttrarna Anna Natalia och Maria gav konserter för gästerna och kunde föra konversation på franska och italienska. ${ }^{59}$ Efter Mottis död år I834 fortsatte hans änka Sara Motti, född Virolainen, framgångsrikt verksamheten. Enligt en historia som återberättats av Esther Höckert och citerats av Sven Hirn var Sara Motti "wie eine Königin", som en drottning, vars uppträdande var "värdigt och automatiskt förskaffade henne människornas aktning". ${ }^{60}$

I tidningarnas uppgifter om värdar och värdinnor för "Anmälda resande" på I830-talet förekom ofta namnen på dessa tre värdshusvärdinnor: Cajsa Wahllund i Helsingfors, Hedvig Astenius i Borgå och Sara Motti i Viborg. Tack vare tidningsuppgifterna kan vi skissera en bild av utländska resande i de värdshus som förestods av dessa kvinnor.

\section{UTL ̈̈NDSKA GÄSTER HOS TRE DUKTIGA VÄRDSHUSVÄRDINNOR}

Gästgivargårdar hade sedan 1762 dagböcker där alla resande måste skriva sitt namn. ${ }^{61} \mathrm{I}$ och med att alla som "emottaga och herbergera

58. Porträttet är publicerat bl.a. i Mårtenson, Fru Astenii värdshus, s. I6.

59. Coxe, Travels into Poland, Russia, Sweden, and Denmark, III, s. 470 f.; Carr, $A$ Northern Summer, s. 213 f.; Johann Gottfrid Seume, Meine Sommer 1805, Leipzig: Reclam 1978 [1806], s. 102 f; Wilson, Travels in Russia, s. 150; Boileau Elliot, Letters from the North of Europe, s. 26r; Jones, Travels in Norway, Sweden, Finland, s. 28r; August von Behr, Meine Reise durch Schlesien, [...] und zurück über Moskau, Petersburg, durch Finland und die Insel Rugen im Sommer 1832, Leipzig: C. F. Hartmann I854, s. 24I f.

6o. Sven Hirn,"Signor Motti”, Lucifer, årg. 47, I958, s. 55-57 (citat). Se även J.W. Ruuth \& Erkki Kuujo, Viipurin kaupungin historia, III osa, vuodet I7IO-I8I2, Viipuri: Torkkelin säätiö I975, 50 f., I39 f.; Soini, Vieraanvaraisuus ammattina I, s. 294-299.

6r. "Kong. Maj:ts nådige Förordning angående det, som hädanefter bör i akttagas wid Gästgifware-Gårdarne i Riket, til förekommande af allehanda olägenheter 
Resande" blev skyldiga att anmäla dem "hos Magistraten eller Politie Borgmästaren" fick gästgivargårdarnas dagböcker en motsvarighet i städerna. Anmälningsskyldigheten gällde både privatpersoner och "Wärdshus- Källare- och Närings-idkare". ${ }^{62}$ Åtminstone i Åbo var magistraten också mycket noga med att värdshusvärdar och -värdinnor alltid anmälde nya resande. ${ }^{63}$ Men det dröjde innan tidningar började publicera namn på "anmälda resande" och hos vem de logerade.

Bland hundratals "anmälda resande" hos Cajsa Wahllund i Helsingfors, med början i januari I829, kan vi särskilja fyra huvudgrupper. Högst bland dem i den dåtida hierarkin stod inhemska och ryska ämbetsmän med titlar upptagna i den officiella rangordningen. ${ }^{64}$ Efter dem kom välbärgade inhemska och utländska handlande, bruksägare och fabrikörer.

Bland Cajsa Wahllunds svenska gäster var Greve Piper sannolikt den namnkunnigaste. ${ }^{65}$ Det fattades inte heller höga finska och ryska ämbetsmän bland hennes gäster. ${ }^{66}$ Att hon hade ett gott rykte i de högsta ryska kretsarna blev klart år I836 då hon fick välkomna "Läraren hos Hans Kejserl. Höghet Thronföljaren, Cesarewitsch [den blivande Alexander II], Hof-Rådet och Riddaren W. v. Jerioz med Fru” och några år senare "Adjutanten hos Hans Kejserl. Höghet, Storfursten Michael Schipoff". ${ }^{67}$

samt hinder och uppehåll för resande, 22 Julii I762", [Modée], Utdrag Utur alla ifrån ${ }_{175} 8$ års slut utkomne Publique Handlingar [...]. Sjunde Delen, til I764 års slut, Stockholm I766, s. 5211, $3 \S, 4$ §.

62. Åbo Allmänna Tidning 23/8 I81o.

63. Cajsa Wahllund blev I8I7 tillsammans med två värdshusvärdar kallad till magistratens möte p.g.a. försummelse av anmälning. Rahikainen, "Urban Opportunities", s. 185 .

64. Om den finska rangordningen, se t.ex. Kaarlo Wirilander, Herrskapsfolk. Ståndsper-

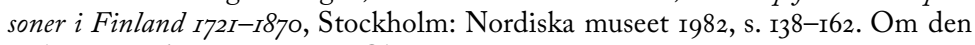
ryska rangordningen, se t.ex. Claes Peterson, Peter the Great's Administrative and Judicial Reforms: Swedish Antecedents and the Process of Reception, Rättshistoriskt bibliotek 29, Stockholm: A.-B. Nordiska Bokhandeln I979, s. Io6-II3.

65. $H \mathrm{I}_{\mathrm{ig}} / 8 \mathrm{I} 835$.

66. Tidningar ifrån Helsingfors 9/I I829, II/I I830, 27/6, I4/7 I831; HT 28/3, 9/9, 9/II I829, 30/6 I832, 5/7 I837, I2/I, I0/8, 28/8 I839, I8/I, 7/3 I840; Helsingfors Morgonblad $(H M)$ I9/ıо, 29/ıo I832, 23/3 I836, 8/9, 25/9 1837, 5/II 1838, 8/9 I837.

67. $H M_{25} / 7$ I836; $H T$ I8/3 I840. Wahllund hade förmodligen ministerstatssekreteraren greve Robert Henrik Rehbinder och hans nära relation till kejsaren att tacka för detta. 
Bland hennes affärsinriktade utländska gäster var svenska, tyska, lybska och preussiska handlande och fabrikörer de mest frekventa, medan norska, brittiska, nederländska, franska och schweiziska var sällsyntare. Vi kan sannolikt räkna med att dessa gäster i värdshuset diskuterade affärer med bland andra Brukspatron Linder av Svartå, Greve Creutz av Malmgård och Greve De Geer av Tervik, som alla tre var ofta sedda gäster hos Cajsa Wahllund.

Den tredje gruppen bland Cajsa Wahllunds utländska gäster, säkert mest uppskattad av helsingforsborna, bestod av olika slags artister: musiker, sångare och aktörer. Hennes värdshus blev först bekant för helsingforsarna som ett ställe där man kunde köpa biljetter till konserter och teaterföreställningar, men snart började gästande teatertrupper och musiker logera i hennes värdshus. ${ }^{68}$ "Biljetter försäljas uti mitt logis hos Mamsell Wahllund" blev en allmän fras i konstnärers teater- och konsertannonser. ${ }^{69}$

Den fjärde gruppen bland Cajsa Wahllunds utländska gäster bestod av utländska yrkesmän som stannade några dagar eller något längre i hennes värdshus och där tog emot sina kunder. Bland dessa yrkesmän fanns en tandläkare vars kompetens täckte "artificiella tänder", en tysk och en svensk "optisk instrumentmakare" och en tysk "KonstTrädgårdsmästare" ${ }^{70}$

Det skulle vara intressant att veta vad gästerna konverserade om vid middagsbordet i Cajsa Wahllunds värdshus. ${ }^{71}$ I september 1829 logerade Greve Rehbinder, Expeditionssekreteraren Mannerheim, amerikanska undersåten Överstelöjtnant Law, Godsägaren Raij från S:t Petersburg och Överstelöjtnant Schulman från Borgå samtidigt hos Cajsa Wahllund. I maj I832 bodde Kapten Ridderståhle, Lieutenanten Munck, preussiska undersåten, Handlande Hösterejl, svenska undersåten Concertmästare Beer med son från Sverige, Musik-Direktorin Heltzel, Stabs Capitaine Oberg och Lieutenanten Melan från Reval

68. von Frenckell, Offentliga nöjen och privata, s. 408-440.

69. T.ex. FAT 6/12 I820, 25/6 I822, I/4 I824, 25/8 I825, 5/10 I826, 8/3, 28/7, 25/9 I827, 23/3 I830, 5/II I832, 26/7 I833, 5/5 I834; $H T$ I6/4 I834, I2/10 I836; $H M$ I6/4 I834, $7 / 8$ I837.

70. FAT I3/2, 4/6 I822, I4/II, 7/I2, 23/I2 I826, 3/II I827; HT 22/I I84O.

71. Under första hälften av I8oo-talet förtärdes middagarna i Helsingfors och S:t Petersburg tidigt på eftermiddagen och de hade ofta karaktären av ett arbetsmöte, även hos kejsaren. 
samt Handlande Wrede från Hamburg samtidigt hos henne. I december 1838 bodde hos henne på samma gång svenska undersåten General Konsul af Forselles, franska undersåtarna bröderna S:t Maur, Doktorerna Bierfreund och Simiroffsky från "Willno"(Vilnius) samt Herr Ekman från Åbo. ${ }^{72}$

I småstaden Borgå logerade resande ståndspersoner ännu hos ståndsfränder medan resande musiker, artister, yrkesmän och handelsmän fann husrum i värdshuset, "hos Fru Astenius". Då Konglig Dansk Kammar-Musikus Ch.L. Kellerman höll en konsert i staden i september 1839, fanns biljetter att tillgå "i undertecknads qvarter hos Fru Astenius". J. Balabrega visade i december I84I sitt konstkabinett i rådhussalen och biljetter såldes "i mitt logi, hos Fru Astenius". Bröderna Strauss, Hof-Optici från Aachen, stannade i januari I84I två dagar i staden och kunde träffas "hos Fru Astenius". I december samma år stannade Bröderna Tietzner, Optici och Mechanici, några dagar i staden. Likaså stod "Tandläkare och Operatör" Hindberg till stadsbornas tjänst "endast några dagar". Särskilt företagsam var S. Moritz som besökte staden två gånger år 1845 . Han hade ett brett sortiment, bland annat barometrar och termometrar,"liktorns-plåster", "en vättska, [...] till utrotande af vägglöss" samt råttsmörja till att "fördriva Råttor och Möss utan giftblandning”. C.G. Bonuvier kom till Borgå med trevligare artiklar: han hyrde ut "maskerad-kostymer, af diverse sorter". Till herrarna i staden sålde J. Arnstam på sin genomresa "silfverbeslagna Sjöskums-Pipor". ${ }^{73}$

Viborg var en viktig och livlig handelsstad och det märktes bland gästerna på Sara Mottis värdshus; inhemska och utländska handlande var välrepresenterade. Viborg hade ett aktivt kulturliv, men särskilt vanliga var inte utländska musiker eller andra uppträdande konstnärer hos Sara Motti. ${ }^{74}$ Värdshuset åtnjöt fortfarande ett gott renommé, och bland Mottis gäster fanns Grevinnan Gowke från Polen och Baron Ungern Sternberg från Estland. ${ }^{75}$ På samma sätt som i Helsingfors och Borgå, stannade utländska yrkesmän några dagar på värdshuset för

72. $H T$ 9/9 I829, I/I2 I $838 ; H M ~ 25 / 5$ I 832.

73. $F A T$ I2/I I84I; $B T$ 8/I2 I84I, I6/3, $24 / 8$ I842, 5/2, 6/I2, 3I/I2 I845.

74. Wiborgs Annonce Blad (WAB) I2/5 I838, 23/4, I3/8 I842.

75. Sanan Saattaja Wiipurista $(S S W) 27 / 6$ I840. Titlarna i SSW översatta till svenska av MR. 
att betjäna ortsborna. Bland dem fanns tandläkare C.F. Lebrecht från Berlin, tandläkare Carl O. Veitt (Russische Kaiserliche Medicinische Facultet), A. Edelberg som sålde glasögon och alla möjliga optiska och meteorologiska instrument samt reparerade sådana, Bröderna Tietzner, Optici och Mecanici, som föregående år besökte Borgå, samt Gymnasist Lehrer August Grasfelt som erbjöd sina tjänster"im Hause der Madame Motti”, i fru Mottis hus. ${ }^{76}$ Bland värdshusets övriga gäster var ett tiotal nationaliteter representerade. ${ }^{77}$

Inhemska och utländska handlande och fabrikörer som tog in på Sara Mottis värdshus diskuterade säkert affärer med varandra. Hos henne befann sig på samma gång i maj I840 franska undersåten Handlanden Lochet, Handelsagent Metzger, Handelsanställde Sjöstedt från Lovisa samt från S:t Petersburg Handlanden Grigorjeff, Handlanden Abramoff och hannoverska undersåten, Handelskommissionär Winkel. Drygt en vecka senare inkvarterade hon amerikanska undersåten Handlande Rand, engelska undersåten Handelsanställde Soers, tyska Handlanden Müller och Handelsanställde Kumlin från Villmanstrand. Två år senare bodde där samtidigt "Würtenbergska" undersåten Handlanden Schmidt från S:t Petersburg, hamburgska medborgaren Handlanden Müller, svenska undersåten Handlanden Lindström, Handlandesonen Ljungström från S:t Petersburg samt Handlanden Galle och Kronofogden Soldan. ${ }^{78}$

Varken hos Cajsa Wahllund, Hedvig Astenius eller Sara Motti logerade någon utländsk kvinna som annonserade om sin yrkeskunskap. Däremot hade Fru Ertmann,"tyska änkan" i Viborg, i sitt värdshus i december 1838 en tyska, Maria Montin. I en tidningsannons erbjöd hon sig att på beställning utföra finare handarbeten åt damer, såsom smycken och prydnader av hår, lockar, blommor, kedjor eller annat material. Hon erbjöd sig också att undervisa damer i dylikt arbete. ${ }^{79}$ Att annonsera på det här sättet i tidningen var inte riktigt

\footnotetext{
76. $S S W$ 24/10 I835, 3/6 I837, 21/3 I840; $W A B$ 22/9 I838, 7/5 I842, 24/2 I844.

77. $S S W 9 / 5,23 / 5,30 / 5$ I $840 ; W A B$ 22/4 I837, 20/8 I842, 22/4, IO/6, 23/6, 23/9 I843, 23/9 I843.

78. $S S W$ 23/5, 30/5 1840; WAB I5/4, 22/4 1837, 28/5, 25/6, 9/7, 16/7, 23/7, 30/7, 13/8, 10/9 $\mathrm{I} 842, \mathrm{I} 7 / 6,8 / 7, \mathrm{I} 2 / 8,22 / 7 \mathrm{I} 843$.

79. $W A B \mathrm{I5} / \mathrm{I} 2 \mathrm{I} 838$.
} 
passande för en anständig kvinna, så det måste ha funnits vägande skäl, såsom nödvändigheten att tjäna sitt uppehälle.

De utländska resebeskrivningarna förmedlar en bild av värdshusvärdinnorna främst som berömvärda eller klandervärda kvinnor vars uppgift var att betjäna resenärerna. Informationen i tidningarnas "anmälda resande"-spalt ger däremot en bild av värdshushållerskorna och -värdinnorna främst som duktiga kvinnor som visste att framgångsrikt sköta sitt välrenommerade företag.

\section{Avsluting}

Ett lands gästgiveriväsen är, skulle man kunna säga, en mätare av dess kulturnivå. Det är ofta den första institution, en resande främling kommer i beröring med, och hans allmänna omdöme om landet blir i mycket beroende av hur han där emottages och vad han får för intryck.

Per Hartmann $1947^{80}$

Värdshus och gästgivargårdar i det tidiga I80o-talets Finland betjänade ortsbor lika ofta som resande. På landsbygden hade bara gästgivargårdar rätt att servera alkoholdrycker. Eftersom gästgivarna ofta deltog aktivt i skötseln av gemensamma angelägenheter i lokalsamfundet, sköttes verksamheten i praktiken ofta av gästgiverskor, deras hustrur. Gästgivare och gästgiverskor var säkert vanare vid att hantera pengar än folk på den finska landsbygden i allmänhet.

I städerna möttes både stadsbor och resande i bättre värdshus. Bättre värdshus var anständiga och socialt neutrala platser att mötas på i ett samhälle där tillträdet till maktens salonger och mötesplatser var strikt ståndsbundet. Så var det också med Cajsa Wahllunds, Hedvig Astenius och Sara Mottis värdshus. I deras restauranger intog utlänningar och stadsbor, musiker, handlande och adelsmän, damer och skådespelerskor sina måltider. I och med tillkomsten av societetshus - på i8ıo-talet i Åbo, i början av I83o-talet i Helsingfors och Viborg,

8o. Per Hartmann, Svenskt gästgiveri genom tiderna, Stockholm: Hans O. Boquist I947, s. 6. 
i slutet av I840-talet i Borgå ${ }^{81}$ - började de bättre värdshusen förefalla förlegade och ersattes av hotell.

Den värld som värdshusvärdinnorna under det tidiga I8oo-talet hörde till försvann för gott. Men det arv de lämnade efter sig, möten mellan främmande och ortsbor i en trevlig miljö skapad av en vänlig värdinna, levde vidare i resandehem i småstäders egnahemshus och i idylliska pensionat för sommargäster på landsbygden och lever vidare i dag i affärskonceptet bed-and-breakfast.

8I. Åsa Ringbom, Societetshusen i Storfurstendömet Finland, Finska Fornminnesföreningens Tidskrift 92, Helsingfors: Finska fornminnesföreningen 1988, s. 18, 24-25. Se även Sven Hirn, Från Wärdshus till Grand Hôtel. Hotell och restauranger i Helsingfors före självständighetstiden, SSLS 693, Helsingfors: SLS 2007. 